\title{
Peer Effects in Microenvironments: The Benefits of Homogeneous Classroom Groups *
}

\author{
Fangwen Lu \\ Renmin University of China \\ lufangwen@ruc.edu.cn
}

\author{
Michael L. Anderson \\ UC Berkeley and NBER \\ mlanderson@berkeley.edu
}

July 25, 2013

\begin{abstract}
Many believe that classroom interactions play an important role in students' academic achievement, but there is little evidence on peer effects within sub-classroom groups. We exploit random seat assignment in a Chinese middle school to estimate how the gender of neighboring students affects a student's academic achievement. We find that being surrounded by five females rather than five males increases a female's test scores by 0.2 to 0.3 standard deviations but has no significant effects on a male's test scores. These results suggest a low-cost way to potentially improve performance within the world's largest school system.
\end{abstract}

JEL Codes: I21, J16

Keywords: Network effects, spillover effects, classroom environment

\footnotetext{
* This study received support from the Fundamental Research Funds for the Central Universities and the Research Funds of Renmin University of China (12XNF018). We thank Jeff Perloff for insightful comments. Any mistakes are the authors' own.
} 


\section{INTRODUCTION}

Social interactions are believed to play an important role in students' academic achievement. Most peer effects studies in primary and secondary education define peers at the classroom or school level and test whether students are influenced by classroom or school-level averages. However, recent work by Carrell, Sacerdote and West (2011) finds that students may form subgroups within larger peer groups, implying that peer effect analyses at the classroom or school level may miss important interactions within subclassroom groups.

This paper examines peer effects among subgroups of Grade 7 students by exploiting an experiment with random seat assignment in a Chinese middle school. As is common in most Chinese schools, students in this school stay at a fixed seat in a fixed classroom for most classes, while teachers rotate through the classrooms. In this experiment, students were assigned to blocks of rows based on height and then randomly assigned to seats within blocks. This within-block randomization controls for non-random sorting of students into groups and allows an exploration of peer effects in a microenvironment (i.e., a sub-classroom group).

We find that the gender of nearby students influences a student's performance, but the effects vary according to the student's gender. For a female student, being surrounded by five females rather than five males increases her test scores by 0.2 to 0.3 standard deviations. For a male student, being surrounded by five males instead of five females does not decrease his test scores, and may increase them by up to 0.1 to 0.3 standard deviations. These effects suggest welfare gains from rearranging students within classrooms. In comparison there is little evidence that baseline test scores of nearby students affect academic performance.

We consider these results in the context of a large set of peer effects models proposed in the literature. We identify one model emphasizing gains from peer group homogeneity - the "Boutique" model - that can plausibly generate our results. We also consider the potential mechanisms underlying our results. We reject the hypothesis that girls improve performance of other girls by reducing disruptions, and instead conclude that cooperative learning behavior is the most likely mechanism underlying our results.

\section{Literature REVIEW}


An extensive theoretical literature explores different models through which academic peer effects may operate (Epple and Romano 2011). More recently, a large set of empirical peer effects studies leverage variation in peer groups at the classroom or school level to estimate peer effects (Hanushek et al. 2003; Angrist and Lang 2004; Arcidiacono and Nicholson 2005; Hoxby and Weingarth 2006; Lyle 2007; Ammermueller and Pischke 2009; Gould, Lavy, and Paserman 2009), and others explore living arrangements among college students (Sacerdote 2001; Zimmerman 2003). The empirical studies generally find evidence of positive spillovers in academic performance. However, to the best of our knowledge no studies leverage experimental or quasi-experimental variation to estimate peer effects within sub-classroom groups.

A related literature explores the effects of student gender on peer outcomes. Morse (1998) and Mael et al. (2005) review observational studies comparing students in single-sex and coeducational classes; some studies suggest single-sex schooling may be beneficial while others indicate no difference. Hoxby (2002) and Lavy and Schlosser (2011) explore plausibly exogenous variation in the gender composition of coeducational schools and find that the proportion of female students has positive effects on students' cognitive achievements. However, gender composition does not have differential effects on boys and girls. Whitmore (2005) finds that students assigned to classrooms with higher proportions female in the Tennessee STAR experiment do better in kindergarten and second grade, with some evidence of differential effects on boys and girls.

Our study extends the rich academic peer effects literature to sub-classroom groups. The results reveal that even within micro-level environments, there can be strong peer effects. This finding has policy relevance because teachers have significant discretion in organizing groups within classrooms. Implementing single-sex groups within classrooms, for example, is less controversial than implementing single-sex classrooms or single-sex schools. Changes to classroom arrangements thus represent a low-cost way to potentially improve academic performance. In addition, our results are consistent with peer effects models that favor "streaming" or homogeneity and inconsistent with peer effects models that emphasize mixing or disruptive students. While our results do not rule out the importance of mixing or disruptive students in other contexts (Figlio 2007), they suggest that disruptive students are not the main source of peer effects in our context. 


\section{SCHOOL ENVIRONMENT}

This experiment was implemented in a coeducational public middle school in Jiangsu, China. At the beginning of the school year, students in Grade 7 - the starting grade - were assigned to a fixed classroom. They stayed in the same classroom for most classes over the semester, while teachers rotated from classroom to classroom. This arrangement is standard for this middle school and most other schools in China. The middle school is not considered an elite school and does not have special entrance requirements.

Desks and benches are provided in classrooms, typically arranged in sets of rows and columns (see Figure 1). Each desk seats two students, and there are four desks per row with aisles between desks. There are six, seven or eight rows in each classroom depending on the number of students. All students are assigned to fixed seats, and they must stay in their assigned seats during class time. The practice of assigning students to fixed seats helps teachers detect absentees and identify students that misbehave during class.

An administrative teacher assigns seats for the classroom. When assigning seats, student height is a major consideration. Classrooms are typically crowded, and taller students sitting in the front may block the view of shorter students behind them. In a nonexperimental setting, the administrative teacher may have personal preferences for assigning seats. For example, some administrative teachers like to put students of the same gender together while others tend to mix genders. Seats may also be dynamically adjusted during the school year as administrative teachers learn more about students. In addition, some parents may request to have their children moved to the front of the classroom or near high performing students.

A typical day consists of a 30-minute reading session in the early morning, four 45minute lecture sessions in the morning, three 45-minute lecture or study sessions in the afternoon, and one 40-minute study or physical exercise session in the late afternoon. During most sessions, students must stay in their own seats. In lectures, chatting is generally prohibited. During study sessions, students choose what to study for themselves. Students are typically allowed to talk in low voice with neighboring students during study sessions.

\footnotetext{
${ }^{1}$ An administrative teacher is a regular teacher with additional managerial responsibilities, which include arranging class events, disciplining misbehavior, communicating with parents, and assigning student seats.
} 
However, seating arrangements remained fixed during study sessions, so in most cases students can only communicate with neighboring students.

Neighboring students have many opportunities to interact with each other, and different peer groups may influence students in different ways. For example, students can talk with their deskmates without moving at all, but they generally have to turn around to talk with students at adjacent desks. Deskmates can always observe each other with ease, but it is difficult to observe details across rows. Though students may interact with other students across aisles, the columns of desks in these classes rotated every several weeks. This rotation is regular school policy, and it ensures that students do not get "stuck" at the edges of classrooms. Students thus had fewer opportunities to form lasting peer groups across aisles.

Since each column of desks stayed together during this experiment, we define peer groups within columns of desks. The first peer group is the desk itself - each student has a single deskmate. The second peer group consists of "neighbor-4 students." A student's neighbor-4 peers are the two students sitting at the desk directly in front of her and the two students sitting at the desk directly behind her. Students sitting across aisles are not a relevant peer group since columns are rotated every few weeks. For students sitting in the first and last row, their neighbor- 4 peers consist of fewer than four students. The last peer group, "neighbor-5 students," consolidates the first two groups. A student's neighbor-5 peers are her neighbor-4 peers plus her deskmate.

To see a concrete example of these peer groups, consider Student 1 in the second row and second column of Figure 1. Student 2 is his deskmate, Students 3 through 6 are his neighbor- 4 peers, and Students 2 through 6 are his neighbor- 5 peers. For Student 3, as no students sit in front of her, her neighbor-4 peers and neighbor-5 peers include only two (1 and 2) and three (1,2, and 4) students respectively.

The classroom layout and rotation of teachers through classrooms is typical of Chinese schools. The characteristics of children in our school, however, may not be representative of the average Chinese child. Table 1 presents summary statistics from the 2000 Chinese Census comparing households in our study's area to the average Chinese household. The school in our study is located in an urban area, so the first two columns of Table 1 compare households living in all Chinese urban areas to households living in our study's urban area. Households in our study's urban area are more educated than households 
in the average Chinese urban area, but they are less likely to have running water or toilets. However, these differences are modest in magnitude even when statistically significant (e.g., less than 0.25 standard deviations). The last two columns of Table 1 compare all Chinese areas to our study's overall area. The differences between the last two columns are even smaller than the differences between the first two columns, perhaps because the sample sizes are larger in the last two columns. For all measures except toilet availability, the urban-rural gap is much larger than the gap between our study area and all Chinese areas. This suggests that the main issue for generalizing our results to other areas in China may be the urbanrural divide rather than the specific area in which we conducted our study.

\section{EXPERIMENTAL DESIGN}

In this experiment, a research group in the local Department of Education randomly assigned students' seats with input from the authors. During the first week of the Fall 2009 semester, the Department of Education requested information on students' names, gender, and heights in each classroom. The basic mechanism for assigning seats is as follows. First, students were sorted from shortest to tallest by gender within each classroom. Then, the first eight students were placed in Block 1 (corresponding to Row 1), the next 16 students were placed in Block 2 (Rows 2 and 3), and the 16-student blocks continued until all students were assigned to blocks. Students taller than 5 feet, 6.5 inches (169 centimeters) were put in a separate block. Finally, a random sequence was generated, and students were randomly permuted and assigned to seats within each block. The size of the last two blocks varies depending on the number of students and distribution students' height within classrooms. Students in shorter groups always sit in front of students in taller groups, but within a block taller students may sit in front of shorter students as a result of the randomization. This did not present challenges in the classroom as all students within the same block are of roughly similar height. Due to the one-child family planning policy and a frequent preference for sons, the ratio of boys to girls was 1.27 in the sample school. As boys and girls were of similar height in Grade 7, we placed four boys and four girls in the first block, and then nine boys and seven girls (1.28 boys per girl) in subsequent blocks until it became infeasible. ${ }^{2}$

\footnotetext{
${ }^{2}$ Boys were 0.4 inches taller than girls on average.
} 
Some students required special seat assignments due to near-sightedness, and in some cases parents lobbied for favorable seat assignments. To increase compliance rates, the researchers allowed administrative teachers to list several student names for favorable seat treatments; students in the favored list account for $9 \%$ of all students. Students on this list received a seat assignment in either a front row or a middle column. ${ }^{3}$ The remaining students in each block were randomly assigned seats. Normal students are thus randomly assigned with respect to their peers, but "favored" students are not randomly assigned with respect to their peers. In particular, favored students are more likely to sit adjacent to other favored students. We thus drop the outcomes for all favored students from our analysis, as these students' seats are not randomly assigned (though our main results are not sensitive to including them). Favored students are still used to construct surrounding peer measures (i.e., the right hand side variables), however; excluding the favored students would introduce measurement error in those measures. We can summarize the assignment procedure as first non-randomly assigning a small number of students, and then randomly assigning the remaining students to the remaining seats. ${ }^{4}$ As an additional precaution, in all regressions we control for deskmate's favored student status and the share of neighbor-4 students that have favored status to ensure that gender and baseline test scores do not serve as proxies for favored student status. Our results are robust to the inclusion or exclusion of these controls.

Administrative teachers were asked to cooperate by adopting the random seat assignments and avoiding seat adjustments over the semester. There were no financial incentives provided to administrative teachers, however, and students were not informed of the research project. It is likely that administrative teachers adjusted seat assignments during the semester so that some students were moved away from their original assignments, but there was no systematic check for compliance in seat arrangement. Strictly speaking, our estimates represent "intent to treat" effects.

\section{DATA AND EMPIRICAL FRAMEWORK}

\footnotetext{
${ }^{3}$ For students on this list, if they were originally assigned to the first four rows, they were moved to the middle columns in the same row. If they were originally in Row 5, they were moved to the middle columns in Row 4. If they were originally behind Row 5 , they were moved to Row 5 .

4 The only confounding factor that the non-random assignment of favored students could introduce would be a correlation between initially sitting near the center of the room and peer characteristics that favored students tend to have. However, we can control for sitting near the center of the room by including column fixed effects. Including these fixed effects does not change our results.
} 
The data for this study consist of three rounds of test scores and two rounds of surveys for students of Grade 7 in Fall 2009. We illustrate the data collection timeline by week of semester in Figure 2. The baseline test and baseline survey were administrated during the first week of the semester before random seat assignment. The random seat assignment was announced during the second week. Students sat according to the random assignment unless the administrative teachers made adjustments. For the midterm and final exams, due to the school's efforts to prevent cheating, students were seated such that students in the same classroom were generally spread over more than ten rooms and no student sat immediately adjacent to another student from the same class. Two teachers monitored the exams in each classroom. The post survey was administrated right after the final exam when students were still seated according the seat arrangement for the final exam. As students took exams and surveys in different seats than their experimental assignments, any correlations in outcomes among randomly assigned peers are not likely generated by communication among students when taking the exams or surveys.

Grading was rigorously conducted. Teachers in the same subjects allocated exam questions among themselves so that the same question was always graded by the same teacher. In addition, students' names were hidden during the grading process. In the baseline test, the school tested students on three major subjects - Chinese, English and math. In the midterm and final, the school tested seven subjects - Chinese, English, math, politics, history, geography, and biology. Each of the three major subjects accounted for 150 points in the raw scores, and the other four subjects accounted for approximately 50 points each. The exam score represents the sum of all seven scores across both the midterm and the final, standardized to have mean 0 and standard deviation $1 .^{5}$ Figure 3 presents the kernel density of students' baseline scores by gender. The test scores are skewed left, and girls had higher scores overall. The distributions of midterm and final scores (not shown) are of similar shape.

In addition to the administrative data on students' gender, height and test scores, the surveys provide information on students' family backgrounds and subjective interests. The

\footnotetext{
5 All of the key results are robust to analyzing the effects on midterm performance and final performance separately.
} 
surveys also report students' evaluations of peer influences. Panel A of Table 2 presents baseline summary statistics, while Panel B presents post-experiment summary statistics.

We use three types of peer groups in this study - deskmates, neighbor-4 peers, and neighbor-5 peers. For each type of peer group, we construct two measures of the peer characteristics: gender composition (whether the deskmate is female or the proportion of females among neighbor- 4 and neighbor- 5 peers) and baseline total test score. Panel $\mathrm{C}$ of Table 2 presents summary statistics of peer characteristics.

Manski (1993) classifies three types of effects that can generate clustering in peer outcomes: correlated effects, endogenous effects, and exogenous effects. Correlated effects arise when similar individuals self select into the same group. The randomized seat assignments eliminate correlated effects. Exogenous effects occur when an individual's predetermined characteristics affect the outcomes of other individuals in the same group. In this research we estimate exogenous effects of gender and baseline test scores. Endogenous effects occur when an individual's outcome affects the outcomes of other individuals in the same group. Endogenous effects are inapplicable to gender (as it is typically an immutable characteristic), but they could arise in the context of test scores. While our focus is on exogenous effects, we test for endogenous effects as well but find no significant evidence of them. ${ }^{6}$

The traditional method for verifying random assignment is to regress baseline characteristics of student $i$ on student $i$ 's peers' characteristics. If the randomization is valid, the coefficients in these regressions should be insignificant. However, since sampling is performed without replacement, a simple bivariate regression may generate mechanical negative correlations. If student $i$ is male, for example, then it is more likely that student $i$ s peers will be female, because the pool of potential peers contains one fewer female (student i). We address this issue by controlling for the average value of the peer characteristic among all students that were eligible to be student is peer (Guryan, Kroft, and Notowidigdo 2009). For example, when testing whether deskmate gender is correlated with student is own gender, we control for the share of females among other students in the same randomization block as student $i$. This should eliminate the mechanical negative correlation. We thus estimate regressions of the form:

${ }^{6}$ Endogenous effects give rise to what Manski terms the "reflection problem," or the difficulty in discerning whether student $i$ s outcome affects student $j$ s outcome or vice versa. Since we focus on exogenous effects, the reflection problem does not arise in our context. 


$$
X_{i, c b}=\alpha_{1} \text { Peer }_{i, c b}+\alpha_{2} \overline{P e e r}_{-i, c b}+\lambda_{c b}+u_{i, c b}
$$

The variable $X_{i, b}$ represents a baseline characteristic for student $i$ in block $b$ of class $c$. The regressor of interest, $P_{e e r} r_{i, b}$, represents the gender or baseline test score of student $i$ s deskmate, neighbor-4, or neighbor-5 students. The regressor $\overline{P e e r}_{-i, c b}$ controls for the average value of the peer characteristic among other students in the same randomization block as student $i$. The term $\lambda_{c b}$ contains block fixed effects; these fixed effects are important for identification since randomization occurs within blocks.

Statistical inference in equation (1) (and all other regressions in our paper) is complicated by the clustered nature of the data. Outcomes are likely correlated within classrooms, and neighbor-4 peer measures are correlated within classrooms by construction - each student belongs to more than one neighbor-4 peer group. One solution is to cluster by classroom, but with only twelve classrooms there are very few clusters, potentially biasing the clustered standard errors. Instead, we use our knowledge of the randomization procedure to perform exact permutation tests. These tests are derived solely from the actual randomization and thus have the appropriate size regardless of the dependence structure of the data (Rosenbaum 2007). In essence, we rerun the experiment 10,000 times and compute the resulting distribution of $t$-statistics. Under the sharp null hypothesis of no treatment effect, this distribution can be used for statistical inference. Unlike cluster bootstrap-based techniques (e.g., Cameron, Gelbach, and Miller 2008), these tests remain valid even for small numbers of clusters, since they are derived from the randomization procedure itself.

To implement the exact permutation tests, we randomly permute the seat assignments according to the original assignment procedure. For each permutation, we calculate Peer ${ }_{i, b}$ based on the permuted seat assignments and estimate equation (1). We then collect the $t$-statistics from 10,000 permutations and compute the distribution of these $t$ statistics. We compare the actual $t$-statistic for a given regression to the distribution of $t$ statistics from the 10,000 random permutations. The $p$-value, reported in italics in all tables, represents the fraction of random permutation $t$-statistics that are larger than the actual $t$ statistic.

Table 3 tests for non-random sorting into peer groups. The table presents results from regressions of student $i$ s predetermined characteristics on peer gender composition (or 
test scores), controlling for block fixed effects and the average value of gender (or test scores) among other students in the same randomization block as student $i$. Each cell represents a separate regression, and permutation-based $p$-values appear in italics.

The subsequent rows of Table 3 test for correlations between student is characteristics and peer gender or peer baseline test scores. Characteristics include height, age, birth order, mother's and father's education, and interest in Chinese, math, and English. The results are consistent with null effects for all tests. Of the 66 tests in Table 3, only two tests, the relationships between age and deskmate gender and birth order and deskmate gender, are statistically significant at the $5 \%$ level $\left(p=0.04\right.$ and 0.05 for these two tests). ${ }^{7}$ Nevertheless, to be conservative we control for baseline characteristics in all subsequent regressions. Our conclusions are unaffected by the inclusion of these controls. If we split the sample by gender and estimate the models in Table 3 separately for males and females, we still find insignificant relationships between each of the baseline characteristics and the peer measures (results available upon request).

The last row of Table 3 tests for correlations between attrition and peer gender or peer baseline test scores. There is a $14 \%$ attrition rate in our main regressions, but almost all of this attrition is due to missing values of baseline covariates rather than missing outcomes (the attrition rate for the midterm exam is $1 \%$ and the attrition rate for the final exam is $0.6 \%$ ). We thus expect attrition to occur randomly, since there is no way for seating assignment to affect the attrition of baseline covariates. Indeed, the last row confirms that there is no significant relationship between attrition and peer gender or baseline test scores.

\section{Results}

\subsection{Main Effects of Peers on Academic Performance}

Given the within-block randomization of seats, we estimate the main effects of peers using the following equation:

$$
Y_{i, c b}=\beta_{1} \text { Peer }_{i, c b}+\gamma X_{i, c b}+\lambda_{c b}+e_{i, c b}
$$

\footnotetext{
${ }^{7}$ Unlike many randomized experiments, we could not mechanically enforce covariate balance by repeating the randomization procedure until all covariate balance tests are statistically insignificant. This is because the randomization procedure was performed prior to the processing of the survey data.
} 
The outcome $Y_{i, c b}$ represents the mean standardized midterm and final scores for student $i$ in block $b$ in class $c$. The regressor of interest, $P_{e e r} r_{i, b}$, represents the gender or baseline test score of student is deskmate or neighbor-4 students. The term $X_{i, c b}$ includes all of student $i$ s baseline characteristics (gender, baseline test score, height, age, birth order, mother's and father's education, and interest in Chinese, math, and English), an indicator for whether student is deskmate is a "favored" student, and the share of "favored" students among student $i$ s neighbor- 4 peers. ${ }^{8}$ The term $\lambda_{c b}$ contains block fixed effects, which are necessary since randomization occurs within blocks. Statistical inference is performed using exact permutation tests, as described in Section 5.

Table 4 presents results from estimating equation (2). Each column represents a separate regression. Column (1) reports results from regressing exam scores on a female deskmate indicator (and the controls listed above). A female deskmate increases a student's test scores by 0.07 standard deviations (s.e. $=0.03$ ). Column (2) reports results from regressing a student's exam scores on his deskmate's baseline score (plus controls). A deskmate's baseline score does not affect student $i$ s exam scores (0.02 standard deviations, s.e. $=0.02)$. Column (3) adds neighbor-4 female share to the specification in column (1), and column (4) adds neighbor-4 baseline scores to the specification in column (2). Adding these measures does not affect the coefficients on deskmate gender or deskmate baseline test scores, which is not surprising since deskmates and neighbor-4 students should be uncorrelated under random seat assignment. The coefficients on the proportion of females among neighbor- 4 students and the baseline test scores of neighbor-4 students are positive (0.03 and 0.04 respectively) but statistically insignificant.

Column (5) presents a regression that includes all four peer measures simultaneously: deskmate gender, deskmate baseline score, neighbor-4 gender, and neighbor-4 baseline score. Only the coefficient on deskmate gender is statistically significant, and its magnitude is unaffected by the inclusion of deskmate or neighbor-4 baseline scores. We can rule out large effects of sitting near students with high baseline scores. For example, we can reject the hypothesis that having a deskmate who scores one standard deviation better on baseline tests increases student $i$ s performance by over 0.05 standard deviations. For neighbor-4 peers we can reject the hypothesis that having four neighbor-4 peers who all score one standard

\footnotetext{
${ }^{8}$ Excluding all baseline characteristics except gender and baseline test score (which are necessary to control for mechanical negative correlation) does not change our conclusions.
} 
deviation better on baseline tests increases student is performance by over 0.10 standard deviations.

\subsection{Heterogeneous Treatment EfFects}

If peer gender has similar effects on test scores for all students, then it is difficult to achieve net improvements on test scores by rearranging students. However, heterogeneous treatment effects are of policy interest because they may provide opportunities for improving aggregate achievement by rearranging students. The first two columns of Panel A in Table 5 present regressions in which we estimate the effects of peer gender composition and baseline scores separately for females (first column) and males (second column). The coefficients on the female deskmate indicator are positive but insignificant for both sexes (0.03 for females and 0.06 for males). For girls, the coefficient on the share of female neighbor-4 students is positive and statistically significant $(0.18$, s.e. $=0.07)$. For boys the coefficient on the share of female neighbor- 4 students is negative and insignificant $(-0.15$, s.e. $=0.11)$. We can rule out large positive effects of neighbor-4 females on boys' exam performance. For example, we can reject the hypothesis that moving a boy from an all-male neighbor-4 environment to an all-female neighbor-4 environment would increase his test scores by more than 0.07 standard deviations. The coefficients on deskmate baseline score and neighbor-4 baseline scores are small and statistically insignificant for both genders.

Column (3) in Table 5 reports differences in the coefficient estimates for females and males. Standard errors for these differences come from a pooled regression in which all regressors are interacted with a female indicator. The difference in the effect of female neighbors on girls and boys is large and statistically significant (0.33 standard deviations, s.e. $=0.13)$. No other differences are statistically significant.

When comparing the effects of deskmates and neighbor-4 students, we cannot reject the hypothesis that both peer types have similar effects. If a neighbor-4 peer exerts the same influence as a deskmate, then the coefficient on the share of female neighbor-4 peers should be four times larger than the female deskmate coefficient. In column (1) the coefficient on share female in neighbor-4 is 6.3 times larger than the female deskmate coefficient. This implies that, for girls, a neighbor-4 student's gender has approximately 1.5 times the impact of her deskmate's gender. We cannot rule out the possibility that this ratio equals unity. For 
boys, the coefficients on the share of female neighbor-4 peers and the female deskmate indicator are of opposite sign in column (2). However, both are statistically insignificant, and we cannot reject the hypothesis that the former is equal to four times the latter.

To evaluate the combined effects of deskmates and neighbor-4 students, Panel B estimates regressions that replace the separate deskmate and neighbor-4 measures with a combined neighbor-5 peer measure (recall that we define student $i$ s neighbor-5 peers as her deskmate plus her neighbor-4 peers). The first column of Panel B demonstrates that female students have positive and statistically significant effects on neighboring female students (0.21 standard deviations, s.e. $=0.08)$. This estimate implies that moving a female student from an all-boy microenvironment to an all-girl microenvironment increases her test scores by approximately 0.2 standard deviations. However, in second column of Panel B, females have no significant effects on neighboring male students, and the point estimate is negative $(-0.12$, s.e. $=0.14)$. The average baseline score of neighbor- 5 students also has no significant effect on exam scores for girls or boys, though we cannot rule out effects as large as 0.1 standard deviations for girls and 0.2 standard deviations for boys.

In column (3) of Panel B, the difference in the effect of female neighbors on girls and boys is 0.33 standard deviations (s.e. $=0.13$ ). To interpret this difference, consider a case in which girl $i$ is surrounded by boys and boy $j$ is surrounded by girls. Swapping the seats of girl $i$ and boy $j$ increases average achievement for these two students by 0.17 standard deviations (i.e., half of 0.33). The coefficients in columns (1) and (2) imply that the effects are stronger for the girl than the boy, but we cannot reject the hypothesis that both genders benefit equally from being surrounded by students of the same gender.

Table 6 presents regressions in which we estimate peer effects separately for students with high- and low-baseline scores. The first column of Panel A presents results from a sample containing only students scoring above the median on the baseline test. All of the peer measures in this sample have coefficients that are close to zero and statistically insignificant. Column (2) of Panel A presents results from a sample containing only students scoring below the median on the baseline test. In this sample the effect of a female deskmate is positive and marginally significant (0.10 standard deviations, s.e. $=0.05)$, but none of the other peer measures are statistically significant. Column (3) reports differences in the 
coefficient estimates for students with high- and low-baseline scores. None of these differences are statistically significant. ${ }^{9}$

Panel B presents regressions that evaluate the overall effects of neighbor-5 students separately for students with high- and low-baseline scores. In both subsamples there are no significant effects of either neighbor gender or neighbor baseline scores. Column (3) reports differences in the neighbor-5 coefficient estimates for students with high-and low-baseline scores. The differences are small and statistically insignificant. We can reject the hypothesis that the neighbor-5 baseline score coefficient for students with high-baseline scores is at least 0.1 standard deviations above the same coefficient for students with low-baseline scores. This implies that, unlike with gender, there is little or no gain to segregating students by aptitude in this context. High-scoring students do not appear to help other high-scoring students more than they help low-scoring students (at least within the variation observed in our data).

Table 7 tests the robustness of our results to dropping the first and last rows from the analysis. Recall that students in the first (last) row have smaller neighbor-4 and neighbor5 groups because there are no students sitting directly behind (ahead) of them. This fact may attenuate our estimates if the effect increases in the number of surrounding students. Dropping the first and last rows from our analysis (but not from the constructed peer measures) increases the effect sizes for both females and males. For females, the effect of moving from an all-boy microenvironment to an all-girl microenvironment - measured by the coefficient on share female of neighbor- 5 students in the first column of Panel B - is now 0.29 standard deviations $($ s.e. $=0.09)$. For males, the effect of moving from an all-boy microenvironment to an all-girl microenvironment, reported in the second column of Panel $\mathrm{B}$, is now -0.32 standard deviations (s.e. $=0.17$ ). This coefficient is marginally significant, suggesting that males may also benefit from gender homogeneous microenvironments.

Table 8 presents regressions in which we separately estimate the effects of "front" and "rear" peer characteristics. We define a student's "front" ("rear") peers to be the two students sitting in the desk directly ahead of (behind) her. ${ }^{10}$ The first column presents a regression in which we estimate the effects of front and rear peer gender composition for females. For girls the coefficient on the share of female front peers is positive and

\footnotetext{
${ }^{9}$ We reach the same conclusions if we instead conduct these tests by interacting the continuous baseline score measure with the peer gender and peer baseline score measures.

${ }^{10}$ In Figure 1, Student 1's front peers are Students 3 and 4, and Student 1's rear peers are Students 5 and 6.
} 
statistically significant $(0.16$, s.e. $=0.06)$, and the coefficient on the share of female rear peers is positive but insignificant $(0.07$, s.e. $=0.06)$. The second column presents a regression in which we estimate the effects of front and rear peer gender composition for males. For boys the coefficient on the share of female front peers students is negative but insignificant (0.11 , s.e. $=0.08)$, and the coefficient on the share of female rear peers is negative and statistically significant $(-0.19$, s.e. $=0.06)$. For both genders the coefficients on front and rear peer baseline scores are small and statistically insignificant.

Column (3) in Table 8 reports differences in the coefficient estimates for females and males. The differences by gender in the effects of female front and rear peers are large and statistically significant. The effect of share female front peers is 0.27 points larger for girls than for boys $($ s.e. $=0.07$ ), and the effect of share female rear peers is 0.26 points larger for girls than for boys (s.e. $=0.07$ ). Overall the results in Table 8 suggest that girls particularly benefit from having other girls seated in front of them, and boys particularly benefit from having other boys seated behind them.

\section{Discussion}

Our experimental results demonstrate that gender homogeneous environments can improve academic outcomes, particularly for girls. However, these "reduced form" estimates do not reveal the structure of peer effects or the mechanisms through which they may operate. While it is impossible to identify a single model explaining our results to the exclusion of all other models, we identify one model - the "Boutique" model - that can plausibly generate our results out of a larger set of models proposed in the literature. We also reject a model - the disruptive student model - that prima facie appears likely as an explanation for our results.

\subsection{Models of Peer Effects}

Hoxby and Weingarth (2006) discuss a series of informal peer effects models in the context of student assignments across schools. We summarize these models here using Hoxby and Weingarth's terminology and, where possible, link them to formal models in the literature. 
The first set of models specifies achievement as a function of mean peer characteristics. The simplest of these models is the Linear-in-Means model, in which student is achievement is a linear function of his or her peers' mean characteristics. The Linear-inMeans model is a special case of the peer effects model developed in Arnott and Rowse (1987); the more general Arnott and Rowse model assumes that peer effects may be a nonlinear function of mean peer characteristics. ${ }^{11}$ Because it assumes that peer effects are homogeneous and operate as a linear function of mean peer characteristics, the Linear-inMeans model has the strong implication that organization of peer groups does not affect aggregate achievement. The more general Arnott and Rowse model implies that mixing (segregation) may improve aggregate achievement, depending on the concavity (convexity) of the function relating mean peer characteristics to student $i$ s achievement.

The second set of models relaxes the assumption that mean peer characteristics are a sufficient statistic for peer influences. These models assume that a single bad (good) student can affect her peers' achievement regardless of how many good (bad) students may offset her in the peer group. Two examples are the Bad Apple and Shining Light models. The former assumes that a single bad student disrupts learning for all his peers, while the latter assumes that a single good student inspires learning for all her peers. Lazear (2001) formalizes the Bad Apple model by assuming that each student has some probability $p$ of disrupting his entire group. Lazear's model implies that smaller groups should learn better and that if $p$ differs across students, total learning is maximized when students are segregated according to $p$.

A third set of models focuses on within-group heterogeneity. The Boutique model assumes that students perform better when surrounded by similar peers. This occurs either because similarity allows students to more easily help each other or because teachers can tailor lessons and materials specifically for students in each group. The Focus model posits that even a student in peer group $j$ who is different than the predominant type in peer group $j$ may benefit from homogeneity because it generates a more cohesive learning environment. The Single Crossing model likewise implies that within-group homogeneity increases aggregate achievement, but only because high-skill students help other high-students more than they help low-skill students. Thus, while the gains in high-skill groups outweigh the

11 Another special case of these models is the Invidious Comparison model. In this model, student $i s$ achievement is negatively related to his peers' average achievement, because higher performing peers lower student $i$ s self esteem. We find no evidence supporting the Invidious Comparison model in our results. 
losses in low-skill groups, segregation is not Pareto improving. In contrast to these models, the Rainbow model assumes that students do better when placed in diverse groups, perhaps because they are exposed to a variety of viewpoints. Epple, Romano, and Sieg (2002, 2003) develop a formal model with similar implications. In their model students are more likely to succeed in the workplace if their peers are representative of society at large. However, in the Epple, Romano, and Sieg model the benefits of heterogeneous peer groups do not become apparent until students enter the labor market.

\subsection{EMPIRICAL Support FOR PeER EfFects Models}

We now review which models are consistent with our empirical results. In the context of our results we primarily consider gender as the relevant peer characteristic rather than baseline test score. Our primary specifications implement a Linear-in-Means model; student is achievement is a function of the proportion female and mean baseline scores among her peers. Unlike the basic Linear-in-Means model, however, we allow for heterogeneous responses by gender or baseline score. Thus our specification does not restrict the organization of peer groups to have zero net effect on aggregate achievement. Our main result that females benefit from sitting near other females, while males do not, strongly rejects the basic Linear-in-Means model. In Appendix Table A1 we consider whether the gender-specific linear specification is sufficient or whether the effects may be nonlinear. Overall we find no evidence of strong nonlinearities in the relationships between a female student's performance and the female share of her neighbor- 5 peers or between a male student's performance and the female share of his neighbor- 5 peers. ${ }^{12}$

Given the well-known behavioral differences between boys and girls, it is tempting to interpret our results using the Bad Apple model or Lazear's disruptive student framework; perhaps being surrounded by girls improves performance because girls are less likely to

\footnotetext{
12 Appendix Table A1 explores whether the effect of neighboring female students is linear in female share. We modify equation (1) to include dummy variables for four categories: female share of neighbor- 5 students is $20-$ $40 \%$, female share of neighbor- 5 students is $40-60 \%$, female share of neighbor- 5 students is $60-80 \%$, and female share of neighbor- 5 students is $80-100 \%$. The omitted category is a female share of neighbor- 5 students from $0-20 \%$. The dummy variable coefficients are estimated with limited precision, but for female students there appears to be a general upward trend in the female share coefficients. Overall there is no evidence of strong nonlinearities in the relationship between a female student's performance and the female share of her neighbor-5 peers. There is also no evidence of a relationship between a male student's performance and the female share of his neighbor-5 peers.
} 
misbehave. However, our results are inconsistent with these models. If boys were detrimental to learning because they were more likely to be disruptive, then we would expect student $i$ to perform worse when surrounded by boys regardless of whether student $i$ is male or female. Our results, however, suggest that if anything males perform better when surrounded by other males. For similar reasons the Shining Light model is also inconsistent with our data; if girls were more "inspirational" to their fellow students than boys, we would expect performance for both genders to increase when surrounded by females. We do not find this.

Another implication of Lazear's disruptive student framework is that what affects student is performance is not the share of potentially disruptive students nearby, but the number of potentially disruptive students nearby. To test this prediction we estimate two specifications. In the first specification student $i$ s performance is a function of the share of males among neighbor-5 students (similar to columns (1) and (2) of Table 5, Panel B). In the second specification student is performance is a function of the number of males among neighbor-5 students. If the disruptive student framework applies, then we expect the second specification to have better explanatory power than the first. In actuality, the reverse is true. Among boys the first specification generates a partial $R^{2}$ of 0.005 while the second specification generates a partial $R^{2}$ of 0.004 . Among girls the first specification generates a partial $R^{2}$ of 0.022 while the second specification generates a partial $R^{2}$ of 0.012 . We thus find no evidence to support the disruptive student framework. ${ }^{13}$

Models focusing on within-group heterogeneity are most relevant to our results. Our results are clearly inconsistent with the Rainbow model since gender heterogeneity decreases performance. Girls do significantly better when seated near other girls, and boys do weakly better when seated near other boys. The Single Crossing model is also inconsistent with our results. In the Single Crossing model, sitting next to girls is beneficial for both girls and boys, but it is more beneficial for girls than boys. Segregation should thus increase total achievement and achievement among girls, but it should decrease achievement among boys.

\footnotetext{
13 Of course, we cannot rule out alternative explanations for these results. The only reason the number of male neighbor- 5 peers is not a linear transformation of the share male of neighbor- 5 peers is that students at the front and back of the classroom have only three peers instead of five. However, students in front (back) rows are also shorter (taller) than students in middle rows. It is thus possible that the model with number of males is in fact the correct model, but that the peer effects in this case are modified by height (or some characteristic correlated with height) in such a way that makes the model with share male fit better. While we view this explanation as somewhat unlikely, we cannot eliminate it.
} 
However, we find no evidence that segregation decreases performance among boys; if anything it appears to increase performance.

The Boutique and Focus models are the most consistent with our results. Both models predict gains to segregation for girls and boys. Discriminating between these two models is difficult, however, because they share similar predictions. The key distinction between the two is that the Focus model predicts that even a student in peer group $j$ who is different than the predominant type in peer group $j$ may benefit from homogeneity because the learning environment is more cohesive. To differentiate between the two models we therefore estimate two specifications. In the first specification student $i$ s performance is a function of the share of females among neighbor-5 students (similar to columns (1) and (2) of Table 5, Panel B). In the second specification student $i$ s performance is a function of the standard deviation of the female indicator in a group comprised of the neighbor- 5 students plus student $i$. The idea is that if homogeneity is beneficial because it generates a more cohesive learning environment regardless of student is gender, then the second specification should have more explanatory power than the first. For example, the second specification allows a female student to perform better when 100\% of neighboring students are male than when $50 \%$ of neighboring students are male. Under the Focus model this occurs because the former environment is more homogeneous than the latter. In actuality, however, the second specification does not fit the data well. Among boys, the first specification generates a partial $R^{2}$ of 0.005 while the second specification generates a partial $R^{2}$ of 0.000 . Among girls, the first specification generates a partial $R^{2}$ of 0.022 while the second specification generates a partial $R^{2}$ of 0.007 . We thus conclude that only the Boutique model, among the models we consider, is consistent with our data.

While our results suggest test score gains from segregation, the Epple, Romano, and Sieg model implies that these gains may come at some future cost. Peer effects in the Epple, Romano, and Sieg model only appear after students enter the labor market. At that point, workplace success is more likely when students have experience working with peers that are representative of society at large. It is thus possible that segregation inhibits development of some non-cognitive skills even as it increases cognitive skills. While we have no empirical evidence regarding this hypothesis, it is worth noting as a limitation when considering the overall costs and benefits of segregating classroom groups. 


\subsection{Mechanisms Underlying Peer Effects}

Our results appear most consistent with the Boutique model of peer effects. However, the model itself describes a data generating process, and there are several mechanisms that may underlie the data generating process. Three mechanisms proposed in the classroom context are: the opportunity for teachers to tailor lessons and materials towards the specific student type (in this case male or female); a decrease in disruptive behavior or confusion within homogeneous groups; and an increase in cooperative learning behavior - or positive interactions - within homogeneous groups.

In contrast to previous studies that define peer groups at the class level, our focus on peer microenvironments rules out the first mechanism, tailoring of lesson plans (a mechanism suggested by the name "Boutique" itself). It is unlikely that teachers can tailor lesson plans to individual clusters since there are roughly 10 non-overlapping clusters of students in each classroom. ${ }^{14}$ We also find little evidence supporting the second mechanism, a reduction in confusion within homogeneous groups. This mechanism is more consistent with the Focus model, which our results in the previous section suggest does not fit our data. Cooperative learning behavior among students of similar gender is thus the most plausible mechanism underlying our results.

For further evidence of cooperative learning behavior in gender homogeneous groups we consider the endpoint survey questions. The endpoint survey includes several questions on the relationship between the surveyed student and his deskmate. Three questions of relevance are: (1) how frequently does the surveyed student communicate with her deskmate; (2) how strongly does the surveyed student wish to remain in her current seat; and (3) how well can the surveyed student concentrate in class. Appendix Table A2 presents results from regressing each of these measures on deskmate and neighbor-4 gender and academic background. We summarize four notable findings here.

First, moving a girl from a microenvironment in which she is surrounded by four boys to a microenvironment in which she is surrounded by four girls reduces the reported frequency of communication with her deskmate by 0.40 standard deviations (s.e. $=0.15$ ). An intuitive explanation for this result is that if a girl communicates more frequently with her

\footnotetext{
${ }^{14}$ Recall also that all specifications include classroom fixed effects, so homogeneity at the cluster level is not confounded with homogeneity at the classroom level.
} 
neighbor-4 peers because they are female, it may crowd out communication with her deskmate. However, since the survey does not ask about communication with neighbor-4 peers, we cannot directly test this hypothesis. Second, boys communicate less frequently with female deskmates than with male deskmates $(-0.21$ standard deviation effect, s.e. $=0.09)$. This result is consistent with gender homogeneity encouraging communication, though it does not explain why males do not appear to benefit from male deskmates. Third, females express a stronger desire to remain in their current seats when they have female deskmates $(0.28$ standard deviation effect, s.e. $=0.13)$. This suggests that females appreciate being seated next to other females. However, there is no significant effect of neighbor-4 gender on seating satisfaction for females, so the evidence is not uniformly consistent. Finally, neither females nor males report better ability to concentrate when sitting next to or nearby girls. This further suggests that the relevant mechanism is not a reduction in disruptive behavior.

Overall the survey results offer suggestive evidence supporting the hypothesis that gender homogenous groups improve outcomes through cooperative learning behavior. There are important caveats, however: statistical power is limited; the results are not uniformly consistent; and the survey does not ask about interactions with neighbor-4 peers.

These caveats notwithstanding, cooperative learning behavior also provides a possible explanation for potential differences in the effects of deskmates and neighbor-4 peers. The overall pattern in Panels A of Tables 5 and 7 suggests that girls benefit from neighbor-4 females, boys benefit from neighbor-4 males, but neither gender benefits strongly from having a deskmate of the same gender. Communication with deskmates is difficult to avoid, but communication with neighbor-4 peers is voluntary and thus may be more dependent on the quality of peer relationships. If students of the same gender are more likely to communicate with each other (as suggested by the first two columns of Appendix Table A2), we might expect larger gains from having neighbor-4 peers of the same gender than from having deskmates of the same gender.

A final consideration is that many of the students in our study are going through puberty (their ages range from 10 to 14). They therefore may be developing an interest in the opposite sex at this juncture and may spend time trying to communicate with classmates of the opposite sex regarding nonacademic matters. If so, students in gender heterogeneous environments may not be disruptive per se, but they may spend less time discussing academic topics than students in gender homogeneous environments. This possibility would 
represent a hybrid of a reduction in "disruptive" behavior and an increase in "cooperative" learning behavior. It is consistent with the evidence in Table 8, which suggests that girls benefit from sitting behind other girls and boys benefit from sitting in front of other boys. If boys turn around to engage in conversation with girls behind them, this could reduce the performance of the boys that are turning around and the girls that they engage. In contrast, boys seated behind girls have no opportunity to even make eye contact with the students in front of them. If this mechanism were important, it would suggest that the external validity of our results could be limited when considering students who have not yet entered puberty.

\section{Conclusion}

We identify peer effects within subgroups inside classrooms by exploiting the random assignment of seats in a Chinese middle school. The results suggest that while having a female deskmate may be beneficial for both boys and girls, having more female neighbors has significant positive effects on girls but potential negative impacts on boys. The differing patterns between the deskmate results and the neighbor-4 results may be due to differences in interactions - interactions between deskmates are easier and to some degree unavoidable, while interactions with neighboring students are voluntary. The most plausible mechanism underlying our findings is the possibility of cooperative learning behavior among students of similar gender.

It is interesting to compare the results of this study to the results of classroom-level and school-level studies on gender peer effects. Whitmore (2005) finds that increasing the classroom female share by 20 percentage points increases kindergarten test scores by approximately 0.1 standard deviations. In comparison, we find that increasing the female share of neighboring students by 20 percentage points increases female test scores by approximately 0.04 standard deviations. Whitmore finds no difference in effects for males and females in kindergarten, but a large difference in effects for males and females in third grade - increasing the female share by 20 percentage points increases female test scores by 0.13 standard deviations but decreases male test scores by 0.16 standard deviations. The implied benefits of gender homogeneity in third grade are consistent with our results.

Lavy and Schlosser (2011) use Israeli data to measure the effect of the fraction female within a school grade level on peer test scores. In eighth grade (the grade closest to 
our study), they find that a 20 percentage point increase in the female share increases female test scores by 0.06 to 0.08 standard deviations on average. These effects are $50 \%$ to $100 \%$ larger than our equivalent effects for neighboring female students. They find no significant effect of female share on eighth grade male test scores. However, a 20 percentage point increase in female share raises high school test scores by 0.04 to 0.05 standard deviations for

both males and females. These effects are similar in magnitude to our effects (for females), but the absence of heterogeneous effects by gender is in contrast to our results.

External validity is a key issue in our study as we focus on one middle school in China. Table 1 establishes that our study's urban area resembles the typical Chinese urban area on several dimensions, but it also reveals the substantial urban-rural divide in China. We would caution against drawing specific conclusions regarding effect sizes in rural Chinese areas or at much younger ages. We are likewise hesitant to extrapolate our results to other countries. The Chinese education system is heavily structured around the classroom and includes in-class study sessions. Furthermore, students stay in the same seat throughout the day and do not switch rooms. This stands in sharp contrast to systems in the United States and the United Kingdom, where middle school students change classrooms many times throughout the day. These frequent room changes ensure that a student's classroom peers are constantly changing, likely affecting how peer relationships impact performance.

These caveats notwithstanding, our results demonstrate the potential for net test score gains from improving classroom arrangements within the Chinese context. This finding suggests a low cost way to improve test scores within a significant segment of the world's largest education system, and it underscores the potential return to further research on peer effects within sub-classroom microenvironments.

\section{REFERENCES}

Ammermueller, Andreas, and Jörn-Steffen Pischke. 2009. "Peer Effects in European Primary Schools: Evidence from the Progress in International Reading Literacy Study." Journal of Labor Economics 27(3): 315-348.

Angrist, Joshua D., and Kevin Lang. 2004. "Does School Integration Generate Peer Effects? Evidence from Boston's Metco Program.” The American Economic Review 94(5): 16131634.

Arcidiacono, Peter, and Sean Nicholson. 2005. "Peer effects in medical school." Journal of 
Public Economics 89(2-3): 327-350.

Arnott, Richard, and John Rowse. 1987. "Peer group effects and educational attainment." Journal of Public Economics 32(3): 287-305.

Cameron, A. Colin, Jonah B. Gelbach, and Douglas L. Miller. 2011. "Bootstrap-Based Improvements for Inference with Clustered Errors." Review of Economics and Statistics 90(3): 414-427.

Carrell, S.E., B.I. Sacerdote, and J.E. West. 2011. "From Natural Variation to Optimal Policy? The Lucas Critique Meets Peer Effects." NBER Working Paper.

Epple, Dennis, and Richard Romano. 2011. "Peer effects in education: A survey of the theory and evidence." Handbook of Social Economics 1(11): 1053-1163.

Epple, Dennis, Richard Romano, and Holger Sieg. 2002. "On the Demographic Composition of Colleges and Universities in Market Equilibrium." The American Economic Review 92(2): 310-314.

- 2003. "Peer effects, financial aid and selection of students into colleges and universities: an empirical analysis." Journal of Applied Econometrics 18(5): 501-525.

Figlio, David N. 2007. "Boys Named Sue: Disruptive Children and Their Peers." Education Finance and Policy 2(4): 376-394.

Gould, Eric D, Victor Lavy, and M. Daniele Paserman. 2009. "Does Immigration Affect the Long-Term Educational Outcomes of Natives? Quasi-Experimental Evidence.” The Economic Journal 119(540): 1243-1269.

Guryan, Jonathan, Kory Kroft, and Matthew J. Notowidigdo. 2009. "Peer Effects in the Workplace: Evidence from Random Groupings in Professional Golf Tournaments." American Economic Journal: Applied Economics 1(4): 34-68.

Hanushek, Eric A et al. 2003. "Does peer ability affect student achievement?" Journal of Applied Econometrics 18(5): 527-544.

Hoxby, C.M., and G. Weingarth. 2006. "Taking race out of the equation: School reassignment and the structure of peer effects."

Hoxby, Caroline M. 2002. "How Does the Makeup of a Classroom Influence Achievement?” Education Next 2(2): 56-63.

Lavy, Victor, and Analía Schlosser. 2011. "Mechanisms and Impacts of Gender Peer Effects at School." American Economic Journal: Applied Economics 3(2): 1-33.

Lazear, Edward P. 2001. "Educational Production.” The Quarterly Journal of Economics 116(3): 777-803.

Lyle, David. 2007. "Estimating and Interpreting Peer and Role Model Effects from 
Randomly Assigned Social Groups at West Point." Review of Economics and Statistics 89(2): 289-299.

Mael, Fred et al. 2005. Single-Sex Versus Coeducational Schooling: A Systematic Review. Jessup, MD: US Department of Education.

Manski, Charles F. 1993. "Identification of Endogenous Social Effects: The Reflection Problem." The Review of Economic Studies 60(3): 531-542.

Morse, S. 1998. Separated by Sex: A Critical Look at Single-Sex Education for Girls. Washington, DC: Amer Assn of Univ Women.

Rosenbaum, Paul R. 2007. "Interference Between Units in Randomized Experiments." Journal of the American Statistical Association 102: 191-200.

Sacerdote, Bruce. 2001. "Peer Effects with Random Assignment: Results for Dartmouth Roommates." The Quarterly Journal of Economics 116(2): 681-704.

Whitmore, Diane. 2005. "Resource and Peer Impacts on Girls' Academic Achievement: Evidence from a Randomized Experiment." The American Economic Review 95(2): 199_ 203.

Zimmerman, David J. 2003. "Peer Effects in Academic Outcomes: Evidence from a Natural Experiment." Review of Economics and Statistics 85(1): 9-23. 
Figure 1: Arrangement of a typical classroom

B 1 a c k b o a r d

\section{Teacher's Desk}

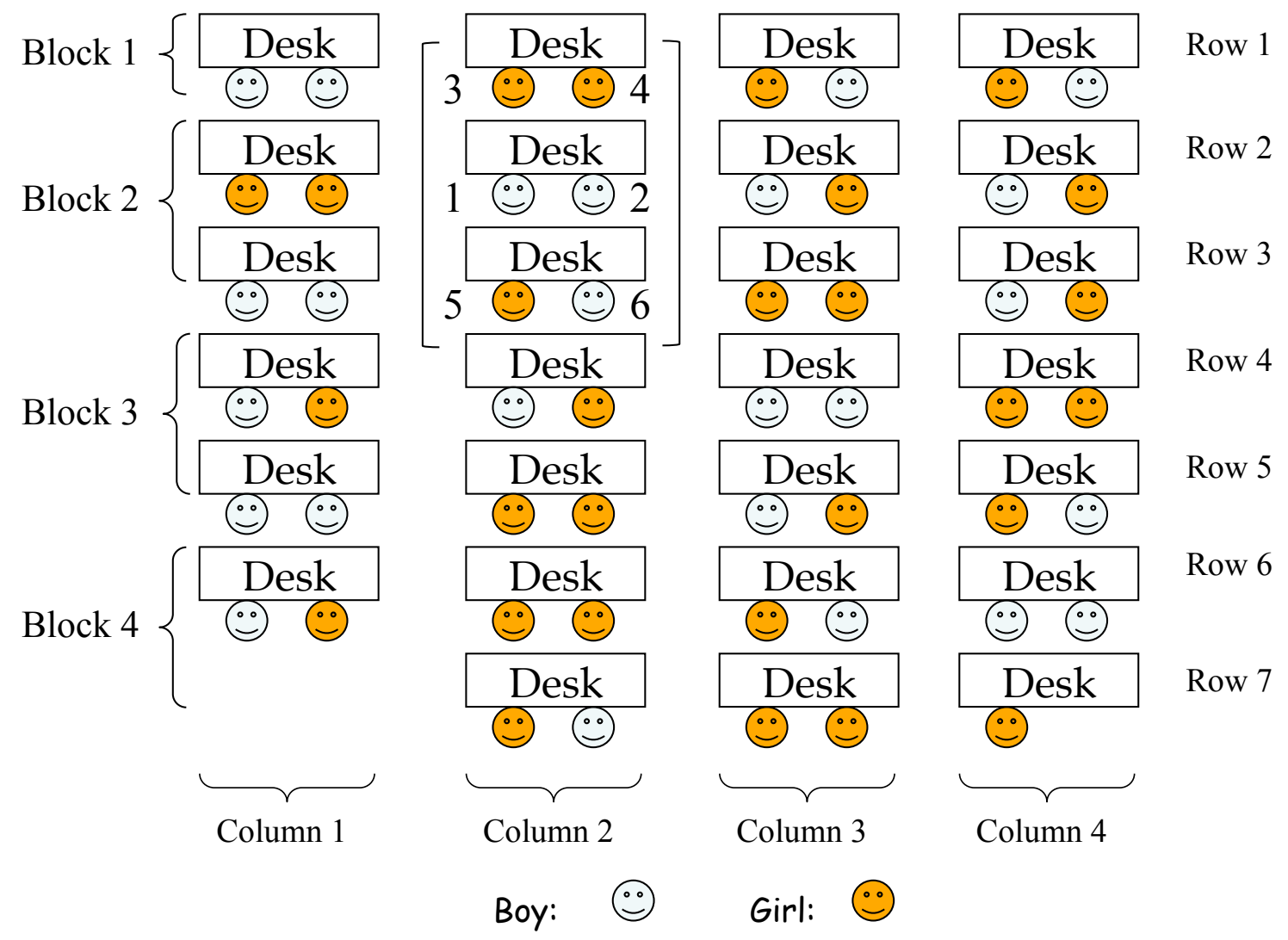

Figure 2: Study timeline

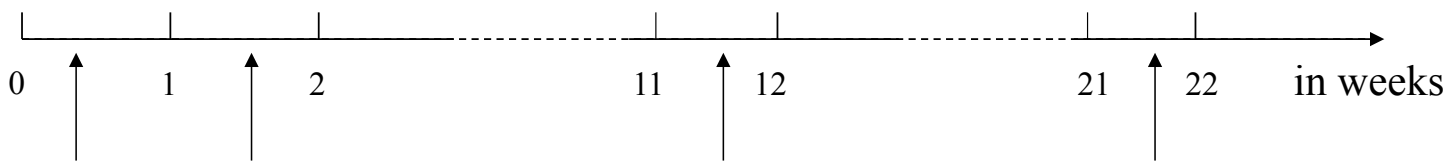

Baseline exams Random seat

Baseline survey assignment

Midterm

Final exams

Post survey 
Figure 3: Distributions of baseline test scores by gender

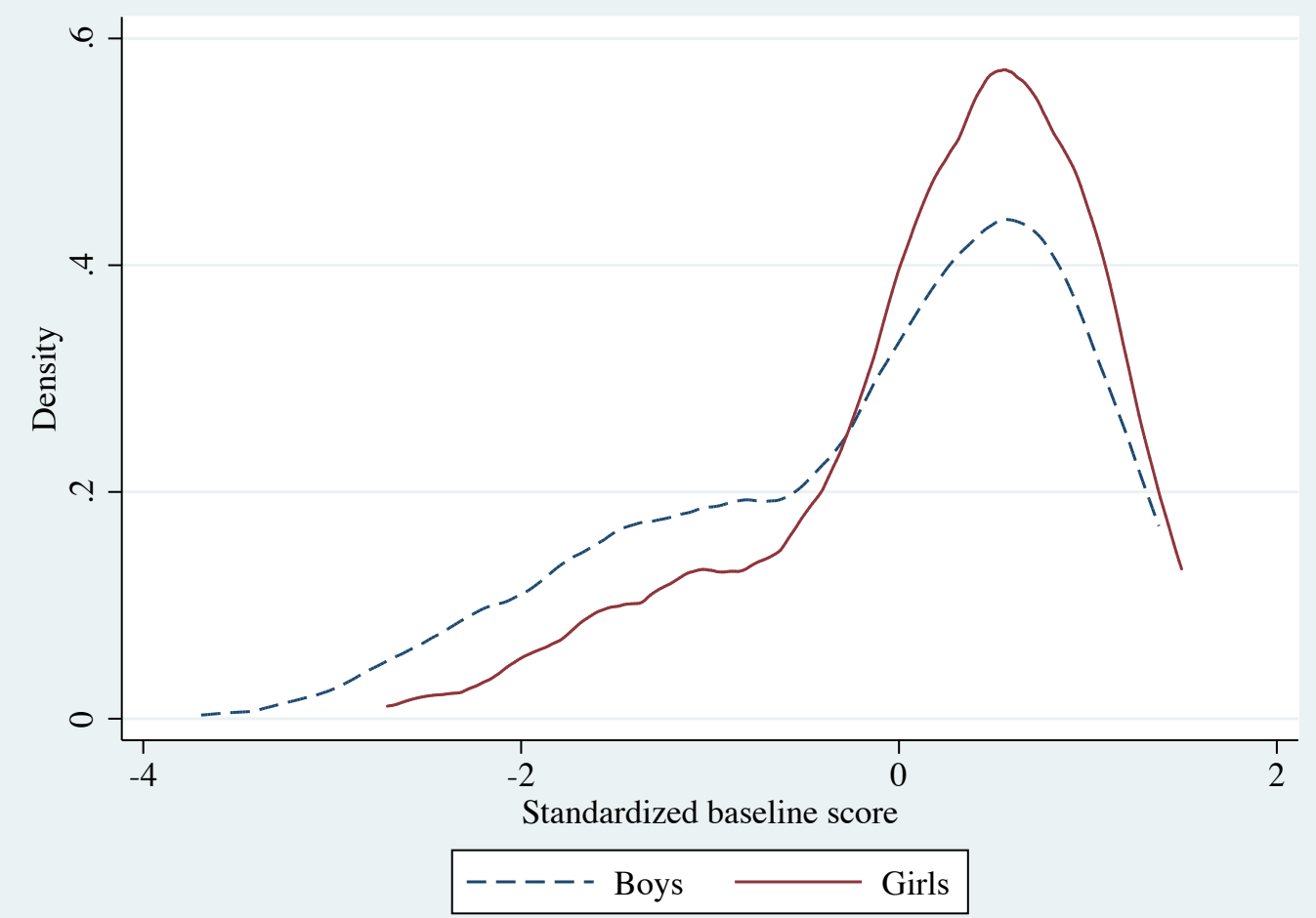

Notes: The solid (dashed) line represents a kernel density plot of standardized baseline test scores for girls (boys) in our sample. Test scores are normalized to have an overall mean of 0 and standard deviation of 1 . 
Table 1: Comparisons Between Study Areas and All Areas

\begin{tabular}{lcccc}
\hline \hline Variable & All Urban & Study Urban & All Areas & Study Area \\
\hline \multirow{2}{*}{ Years of Education } & 10.2 & 10.3 & 8.8 & 8.8 \\
& $(2.8)$ & $(2.6)$ & $(2.8)$ & $(2.4)$ \\
Education $\geq 9$ years & 0.87 & $0.91^{*}$ & 0.72 & $0.75^{*}$ \\
& $(0.33)$ & $(0.28)$ & $(0.45)$ & $(0.44)$ \\
HH size & 4.0 & 4.0 & 4.2 & 4.3 \\
& $(1.5)$ & $(1.4)$ & $(1.5)$ & $(1.4)$ \\
Running water available & 0.77 & 0.75 & 0.40 & 0.42 \\
& $(0.42)$ & $(0.44)$ & $(0.49)$ & $(0.49)$ \\
Toilet available & 0.74 & 0.63 & 0.70 & $0.76 *$ \\
& $(0.44)$ & $(0.49)$ & $(0.46)$ & $(0.43)$ \\
Households & 16,864 & 51 & 53,300 & 186 \\
\hline
\end{tabular}

Notes: Standard deviations in parentheses. ${ }^{*}$ denotes statistically different than All Urban/All Areas average at $5 \%$ level. Data come from a $0.1 \%$ sample of the 2000 Chinese Census. 
Table 2: Summary Statistics

\begin{tabular}{|c|c|c|c|c|c|}
\hline Variable & Observations & Mean & Std. Dev. & Min & $\overline{\mathrm{Max}}$ \\
\hline \multicolumn{6}{|l|}{ Panel A: Baseline characteristics } \\
\hline Female & 682 & 0.43 & 0.5 & 0 & 1 \\
\hline Baseline test score & 680 & 0.00 & 1.00 & -3.69 & 1.50 \\
\hline "Favored" student & 682 & 0.09 & 0.29 & 0 & 1 \\
\hline Body height $(\mathrm{cm})$ & 682 & 156.43 & 6.71 & 135 & 180 \\
\hline Age (years) & 655 & 12.47 & 0.55 & 10.17 & 14.75 \\
\hline Birth Order & 680 & 1.42 & 0.75 & 1 & 7 \\
\hline Father's education & 650 & 11.65 & 3.04 & 3 & 19 \\
\hline Mother's education & 647 & 10.84 & 3.07 & 3 & 19 \\
\hline Interest in Chinese (pre) & 643 & 4.02 & 0.81 & 1 & 5 \\
\hline Interest in English (pre) & 638 & 3.93 & 1.05 & 1 & 5 \\
\hline Interest in Math (pre) & 643 & 4.05 & 0.85 & 1 & 5 \\
\hline \multicolumn{6}{|l|}{ Panel B: Post experiment characteristics } \\
\hline Midterm score & 675 & 0.00 & 1.01 & -3.12 & 1.57 \\
\hline Final score & 677 & 0.01 & 1.01 & -2.83 & 1.66 \\
\hline $\begin{array}{l}\text { Effects of deskmate on student } i \text { s } \\
\text { study }\end{array}$ & 663 & 3.33 & 1.04 & 1 & 5 \\
\hline $\begin{array}{l}\text { Effects of student } i \text { on deskmate's } \\
\text { study }\end{array}$ & 661 & 3.48 & 0.86 & 1 & 5 \\
\hline Relations with deskmate & 661 & 3.74 & 1.13 & 1 & 5 \\
\hline Desire to change seats & 669 & 3.34 & 1.34 & 1 & 5 \\
\hline \multicolumn{6}{|l|}{ Panel C: Characteristics of peers } \\
\hline Female deskmate & 672 & 0.44 & 0.5 & 0 & 1 \\
\hline $\begin{array}{l}\% \text { females in surrounding } 4 \\
\text { students }\end{array}$ & 682 & 0.44 & 0.27 & 0 & 1 \\
\hline $\begin{array}{l}\% \text { females in surrounding } 5 \\
\text { students }\end{array}$ & 682 & 0.44 & 0.24 & 0 & 1 \\
\hline Baseline score of deskmate & 670 & 0.001 & 1 & -3.69 & 1.5 \\
\hline $\begin{array}{l}\text { Average baseline score of } \\
\text { surrounding } 4 \text { students }\end{array}$ & 682 & -0.001 & 0.57 & -2.33 & 1.31 \\
\hline $\begin{array}{l}\text { Average baseline score of } \\
\text { surrounding } 5 \text { students }\end{array}$ & 682 & 0 & 0.5 & -1.97 & 1.31 \\
\hline
\end{tabular}


Table 3: Relationships Between Peer Measures and Baseline Characteristics

\begin{tabular}{|c|c|c|c|c|c|c|}
\hline $\begin{array}{r}\text { Peer measure } \\
\text { (independent variable): }\end{array}$ & $\begin{array}{c}\text { Deskmate } \\
\text { female }\end{array}$ & $\begin{array}{l}\text { Neighbor-4 } \\
\text { female share }\end{array}$ & $\begin{array}{l}\text { Neighbor-5 } \\
\text { female share }\end{array}$ & $\begin{array}{c}\text { Deskmate } \\
\text { score }\end{array}$ & $\begin{array}{l}\text { Neighbor-4 } \\
\text { avg score }\end{array}$ & $\begin{array}{c}\text { Neighbor-5 } \\
\text { avg score }\end{array}$ \\
\hline $\begin{array}{l}\text { Baseline characteristic (dependent } \\
\text { variable): }\end{array}$ & & & & & & \\
\hline Female & $\begin{array}{c}0.011 \\
(0.028) \\
0.700\end{array}$ & $\begin{array}{c}-0.103 \\
(0.068) \\
0.315\end{array}$ & $\begin{array}{c}-0.102 \\
(0.085) \\
0.263\end{array}$ & $\begin{array}{c}-0.003 \\
(0.006) \\
0.626\end{array}$ & $\begin{array}{c}0.023 \\
(0.018) \\
0.227\end{array}$ & $\begin{array}{c}0.023 \\
(0.021) \\
0.306\end{array}$ \\
\hline Baseline test score & $\begin{array}{c}0.038 \\
(0.038) \\
0.557\end{array}$ & $\begin{array}{c}0.086 \\
(0.095) \\
0.391\end{array}$ & $\begin{array}{c}0.166 \\
(0.130) \\
0.235\end{array}$ & $\begin{array}{c}0.020 \\
(0.018) \\
0.302\end{array}$ & $\begin{array}{c}-0.118 \\
(0.084) \\
0.185\end{array}$ & $\begin{array}{c}-0.135 \\
(0.117) \\
0.290\end{array}$ \\
\hline Height (cm) & $\begin{array}{c}0.166 \\
(0.195) \\
0.656\end{array}$ & $\begin{array}{c}0.487 \\
(0.675) \\
0.497\end{array}$ & $\begin{array}{c}0.772 \\
(0.744) \\
0.328\end{array}$ & $\begin{array}{c}-0.079 \\
(0.103) \\
0.474\end{array}$ & $\begin{array}{c}0.155 \\
(0.236) \\
0.539\end{array}$ & $\begin{array}{c}0.119 \\
(0.276) \\
0.679\end{array}$ \\
\hline Age (years) & $\begin{array}{c}-0.069 \\
(0.029) \\
0.038\end{array}$ & $\begin{array}{c}0.022 \\
(0.098) \\
0.824\end{array}$ & $\begin{array}{c}-0.071 \\
(0.115) \\
0.557\end{array}$ & $\begin{array}{c}-0.018 \\
(0.027) \\
0.520\end{array}$ & $\begin{array}{c}0.033 \\
(0.041) \\
0.448\end{array}$ & $\begin{array}{c}0.008 \\
(0.041) \\
0.855\end{array}$ \\
\hline Birth Order & $\begin{array}{c}-0.124 \\
(0.057) \\
0.049\end{array}$ & $\begin{array}{c}-0.102 \\
(0.139) \\
0.486\end{array}$ & $\begin{array}{c}-0.258 \\
(0.135) \\
0.085\end{array}$ & $\begin{array}{c}0.002 \\
(0.032) \\
0.956\end{array}$ & $\begin{array}{c}-0.123 \\
(0.063) \\
0.074\end{array}$ & $\begin{array}{c}-0.130 \\
(0.071) \\
0.109\end{array}$ \\
\hline Father's education & $\begin{array}{c}0.164 \\
(0.321) \\
0.799\end{array}$ & $\begin{array}{c}0.398 \\
(0.609) \\
0.537\end{array}$ & $\begin{array}{c}0.743 \\
(0.646) \\
0.280\end{array}$ & $\begin{array}{c}-0.139 \\
(0.144) \\
0.351\end{array}$ & $\begin{array}{c}0.179 \\
(0.210) \\
0.412\end{array}$ & $\begin{array}{c}0.027 \\
(0.328) \\
0.938\end{array}$ \\
\hline Mother's education & $\begin{array}{c}-0.059 \\
(0.206) \\
0.778\end{array}$ & $\begin{array}{c}0.658 \\
(0.328) \\
0.076\end{array}$ & $\begin{array}{c}0.671 \\
(0.313) \\
0.062\end{array}$ & $\begin{array}{c}-0.040 \\
(0.085) \\
0.652\end{array}$ & $\begin{array}{c}-0.140 \\
(0.281) \\
0.629\end{array}$ & $\begin{array}{c}-0.170 \\
(0.329) \\
0.625\end{array}$ \\
\hline Interest in Chinese (pre) & $\begin{array}{c}0.056 \\
(0.068) \\
0.461\end{array}$ & $\begin{array}{c}0.022 \\
(0.153) \\
0.889\end{array}$ & $\begin{array}{c}0.071 \\
(0.131) \\
0.616\end{array}$ & $\begin{array}{c}-0.060 \\
(0.032) \\
0.089\end{array}$ & $\begin{array}{c}0.063 \\
(0.046) \\
0.209\end{array}$ & $\begin{array}{c}-0.013 \\
(0.047) \\
0.788\end{array}$ \\
\hline Interest in English (pre) & $\begin{array}{c}0.126 \\
(0.068) \\
0.113\end{array}$ & $\begin{array}{c}-0.133 \\
(0.152) \\
0.407\end{array}$ & $\begin{array}{c}0.008 \\
(0.160) \\
0.956\end{array}$ & $\begin{array}{c}-0.046 \\
(0.033) \\
0.199\end{array}$ & $\begin{array}{c}-0.035 \\
(0.062) \\
0.611\end{array}$ & $\begin{array}{c}-0.095 \\
(0.065) \\
0.171\end{array}$ \\
\hline Interest in Math (pre) & $\begin{array}{c}-0.065 \\
(0.045) \\
0.162\end{array}$ & $\begin{array}{c}-0.075 \\
(0.119) \\
0.544\end{array}$ & $\begin{array}{c}-0.162 \\
(0.125) \\
0.225\end{array}$ & $\begin{array}{c}-0.007 \\
(0.021) \\
0.747\end{array}$ & $\begin{array}{c}0.011 \\
(0.093) \\
0.916\end{array}$ & $\begin{array}{c}-0.005 \\
(0.104) \\
0.964\end{array}$ \\
\hline Missing Any Covariate Values & $\begin{array}{c}0.009 \\
(0.035) \\
0.867\end{array}$ & $\begin{array}{c}-0.023 \\
(0.050) \\
0.655\end{array}$ & $\begin{array}{c}-0.020 \\
(0.072) \\
0.790\end{array}$ & $\begin{array}{c}0.011 \\
(0.016) \\
0.505\end{array}$ & $\begin{array}{c}-0.016 \\
(0.044) \\
0.722\end{array}$ & $\begin{array}{c}-0.002 \\
(0.040) \\
0.966\end{array}$ \\
\hline
\end{tabular}

Notes: Each cell represents a separate regression. The cell in row $i$ and column $j$ reports the results from a regression of the dependent variable in row $i$ on the peer measure in column $j$. "Favored" students with non-random seat assignments are excluded. All regressions control for gender and baseline test score of other students in the same randomization block. Parentheses contain standard errors clustered by classroom. Permutation-based p-values are reported in italics. 
Table 4: Effects of Peer Gender and Baseline Score on Test Scores

\begin{tabular}{|c|c|c|c|c|c|}
\hline \multirow[t]{2}{*}{ Dependent variable: } & \multicolumn{5}{|c|}{ Exam Score (Midterm + Final) } \\
\hline & $(1)$ & (2) & (3) & (4) & (5) \\
\hline \multicolumn{6}{|l|}{ Peer measures (independent variables): } \\
\hline Female deskmate & $\begin{array}{c}0.070 \\
(0.027) \\
0.024\end{array}$ & & $\begin{array}{c}0.071 \\
(0.027) \\
0.023\end{array}$ & & $\begin{array}{c}0.065 \\
(0.028) \\
0.039\end{array}$ \\
\hline Baseline score of deskmate & & $\begin{array}{c}0.018 \\
(0.018) \\
0.344\end{array}$ & & $\begin{array}{c}0.019 \\
(0.019) \\
0.343\end{array}$ & $\begin{array}{c}0.012 \\
(0.019) \\
0.548\end{array}$ \\
\hline Share female in Neighbor-4 & & & $\begin{array}{c}0.034 \\
(0.085) \\
0.702\end{array}$ & & $\begin{array}{c}0.018 \\
(0.082) \\
0.840\end{array}$ \\
\hline Avg baseline score of Neighbor- 4 & & & & $\begin{array}{c}0.039 \\
(0.030) \\
0.219\end{array}$ & $\begin{array}{c}0.034 \\
(0.031) \\
0.299\end{array}$ \\
\hline Observations & 532 & 532 & 532 & 532 & 532 \\
\hline
\end{tabular}

Notes: Each column represents a separate regression of the dependent variable on one or more of the listed peer measures. "Favored" students with non-random seat assignments are excluded from the sample. All regressions control for gender, baseline test score, proximity of "favored" students, height, age, birth order, parental education, and baseline interest in Chinese, English, and math. Parentheses contain standard errors clustered by classroom. Permutation-based pvalues are reported in italics. 
Table 5: Effects of Peer Gender and Baseline Score on Test Scores for Females and Males

\begin{tabular}{llcc}
\hline \hline Dependent variable: & \multicolumn{3}{c}{ Exam Score (Midterm + Final) } \\
\cline { 2 - 4 } Sample: & Female & Male & $\begin{array}{l}\text { Female/Male } \\
\text { Coefficient } \\
\text { Difference }\end{array}$ \\
\hline
\end{tabular}

Panel A: Regressions with deskmate and Neighbor-4 measures

Peer measures (independent variables):

Female deskmate

$\begin{array}{ccc}0.029 & 0.061 & -0.032 \\ (0.042) & (0.053) & (0.059) \\ 0.514 & 0.286 & 0.651\end{array}$

Baseline score of deskmate

$\begin{array}{ccc}0.034 & 0.005 & 0.029 \\ (0.016) & (0.035) & (0.040) \\ 0.057 & 0.889 & 0.460\end{array}$

Share female in Neighbor-4

$\begin{array}{ccc}0.182 & -0.152 & 0.334 \\ (0.073) & (0.114) & (0.128) \\ 0.033 & 0.221 & 0.027\end{array}$

Avg baseline score of Neighbor-4

$\begin{array}{ccc}-0.023 & 0.089 & -0.112 \\ (0.061) & (0.063) & (0.105) \\ 0.711 & 0.203 & 0.228\end{array}$

Panel B: Regressions with Neighbor-5 measures

Peer measures (independent variables):

Share female in Neighbor-5

$\begin{array}{ccc}0.211 & -0.121 & 0.332 \\ (0.076) & (0.139) & (0.132) \\ 0.021 & 0.408 & 0.057\end{array}$

Avg baseline score of Neighbor-5

$\begin{array}{ccc}0.012 & 0.101 & -0.089 \\ (0.060) & (0.084) & (0.120) \\ 0.838 & 0.260 & 0.406\end{array}$

Observations 245 287

Notes: Within each panel, each column represents a separate regression of the dependent variable on the peer measures listed in that panel. "Favored" students with non-random seat assignments are excluded from all samples. All regressions control for baseline test score, proximity of "favored" students, height, age, birth order, parental education, and baseline interest in Chinese, English, and math. Parentheses contain standard errors clustered by classroom. Standard errors for the difference in female and male coefficients come from a pooled regression in which every regressor is interacted with a female indicator. Permutation-based p-values are reported in italics. 
Table 6: Effects of Peer Gender and Baseline Score on Test Scores for High- and Low-Scoring Students

\begin{tabular}{lccc}
\hline \hline Dependent variable: & \multicolumn{3}{c}{ Exam Score (Midterm + Final) } \\
\cline { 2 - 4 } & $(1)$ & $(2)$ & $(3)$ \\
\hline \multirow{2}{*}{ Sample: } & High Baseline & Low Baseline & High/Low \\
& Score & Score & Coefficient \\
& & & Difference \\
\hline
\end{tabular}

Panel A: Regressions with deskmate and Neighbor-4 measures

Peer measures (independent variables):

\begin{tabular}{lccc} 
Female deskmate & 0.025 & 0.104 & -0.079 \\
& $(0.043)$ & $(0.048)$ & $(0.074)$ \\
& 0.578 & 0.057 & 0.245 \\
& & & \\
Baseline score of deskmate & 0.001 & 0.016 & -0.015 \\
& $(0.022)$ & $(0.025)$ & $(0.027)$ \\
& 0.965 & 0.542 & 0.660 \\
Share female in Neighbor-4 & 0.031 & -0.114 & 0.145 \\
& $(0.053)$ & $(0.141)$ & $(0.128)$ \\
& 0.576 & 0.457 & 0.362 \\
Avg baseline score of Neighbor-4 & 0.020 & 0.065 & -0.045 \\
& $(0.032)$ & $(0.063)$ & $(0.066)$ \\
& 0.548 & 0.337 & 0.540 \\
\hline Panel B: Regressions with Neighbor-5 measures & & \\
Peer measures (independent variables): & & & \\
Share female in Neighbor-5 & 0.045 & -0.026 & 0.071 \\
& $(0.082)$ & $(0.152)$ & $(0.144)$ \\
& 0.604 & 0.870 & 0.691 \\
& & & \\
& 0.032 & 0.071 & -0.039 \\
Avg baseline score of Neighbor-5 & $(0.042)$ & $(0.072)$ & $(0.079)$ \\
& 0.470 & 0.358 & 0.653
\end{tabular}

Observations

$267 \quad 265$

Notes: Within each panel, each column represents a separate regression of the dependent variable on the peer measures listed in that panel. "Favored" students with non-random seat assignments are excluded from all samples. All regressions control for gender, baseline test score, proximity of "favored" students, height, age, birth order, parental education, and baseline interest in Chinese, English, and math. Parentheses contain standard errors clustered by classroom. Standard errors for the difference in lowand high-score student coefficients come from a pooled regression in which every regressor is interacted with a high-baseline score indicator. Permutation-based p-values are reported in italics. 
Table 7: Effects of Peer Gender and Baseline Score on Test Scores for Females and Males (Front and Rear Rows Dropped)

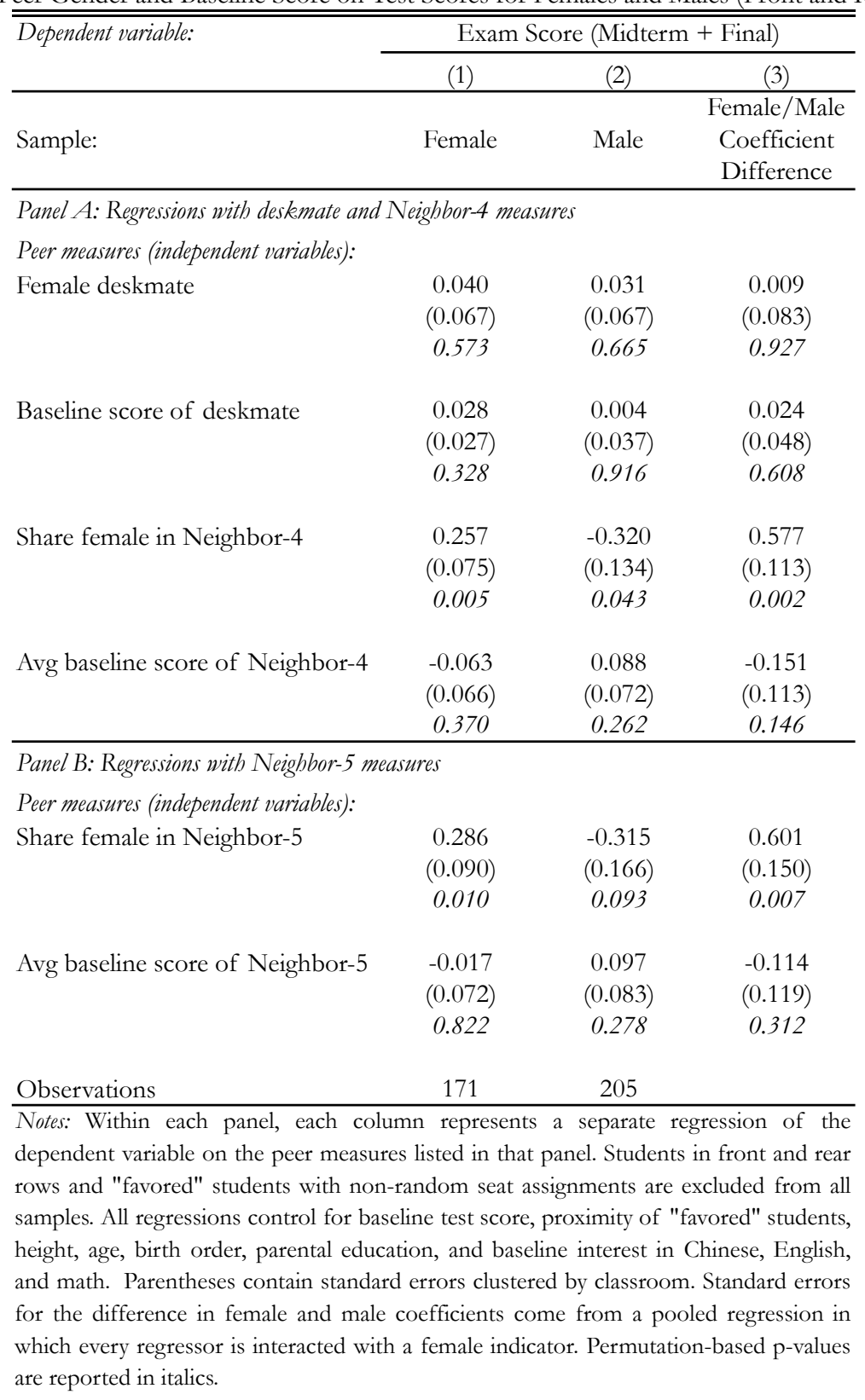


Table 8: Effects of Front and Rear Peers on Test Scores for Females and Males

\begin{tabular}{|c|c|c|c|}
\hline \multirow[t]{2}{*}{ Dependent variable: } & \multicolumn{3}{|c|}{ Exam Score (Midterm + Final) } \\
\hline & $(1)$ & (2) & (3) \\
\hline Sample: & Female & Male & $\begin{array}{c}\text { Female/Male } \\
\text { Coefficient } \\
\text { Difference }\end{array}$ \\
\hline \multicolumn{4}{|l|}{ Peer measures (independent variables): } \\
\hline Share female in front peers & $\begin{array}{c}0.162 \\
(0.058) \\
0.019\end{array}$ & $\begin{array}{c}-0.112 \\
(0.077) \\
0.190\end{array}$ & $\begin{array}{c}0.274 \\
(0.068) \\
0.001\end{array}$ \\
\hline Avg baseline score of front peers & $\begin{array}{c}-0.066 \\
(0.043) \\
0.154\end{array}$ & $\begin{array}{c}0.041 \\
(0.037) \\
0.307\end{array}$ & $\begin{array}{c}-0.107 \\
(0.063) \\
0.114\end{array}$ \\
\hline Share female in rear peers & $\begin{array}{c}0.066 \\
(0.059) \\
0.290\end{array}$ & $\begin{array}{c}-0.191 \\
(0.058) \\
0.009\end{array}$ & $\begin{array}{c}0.257 \\
(0.070) \\
0.001\end{array}$ \\
\hline Avg baseline score of rear peers & $\begin{array}{c}-0.007 \\
(0.049) \\
0.893\end{array}$ & $\begin{array}{c}0.053 \\
(0.049) \\
0.316\end{array}$ & $\begin{array}{c}-0.059 \\
(0.076) \\
0.452\end{array}$ \\
\hline Observations & 180 & 215 & \\
\hline \multicolumn{4}{|c|}{$\begin{array}{l}\text { Notes: Each column represents a separate regression of the dependent variable on the } \\
\text { peer measures listed in that panel. Student } i \text { 's "front" ("rear") peers are the two students } \\
\text { seated in front of (behind) student } i \text {. "Favored" students with non-random seat } \\
\text { assignments are excluded from all samples. All regressions control for baseline test } \\
\text { score, proximity of "favored" students, deskmate gender and baseline score, height, age, } \\
\text { birth order, parental education, and baseline interest in Chinese, English, and math. } \\
\text { Parentheses contain standard errors clustered by classroom. Standard errors for the } \\
\text { difference in female and male coefficients come from a pooled regression in which } \\
\text { every regressor is interacted with a female indicator. Permutation-based p-values are } \\
\text { reported in italics. }\end{array}$} \\
\hline
\end{tabular}


Table A1: Nonlinear Effects of Peer Gender and Baseline Score on Test Scores for Females and Males

\begin{tabular}{lcc}
\hline \hline $\begin{array}{l}\text { Dependent variable: } \\
\text { Sample: }\end{array}$ & \multicolumn{2}{c}{$\begin{array}{c}\text { Exam Score } \\
\text { (Midterm }+ \text { Final) }\end{array}$} \\
$\begin{array}{l}\text { Peer measures (independent } \\
\text { variables): }\end{array}$ & Female & Male \\
20-40\% females in & & \\
Neighbor-5 & & \\
& 0.059 & -0.002 \\
& $(0.118)$ & $(0.172)$ \\
& 0.643 & 0.991
\end{tabular}

$40-60 \%$ females in

Neighbor- 5

$0.021-0.058$

$(0.107) \quad(0.163)$

$0.857 \quad 0.747$

$60-80 \%$ females in

$\begin{array}{ccc}\text { Neighbor-5 } & 0.155 & -0.042 \\ & (0.086) & (0.174) \\ & 0.115 & 0.828\end{array}$

$80-100 \%$ females in

Neighbor-5

$\begin{array}{cc}0.192 & -0.127 \\ (0.120) & (0.236) \\ 0.168 & 0.630\end{array}$

Avg baseline score of

Neighbor-5

$\begin{array}{cc}0.016 & 0.100 \\ (0.061) & (0.085) \\ 0.794 & 0.273\end{array}$

Observations

245

287

Notes: Each column represents a separate regression of the dependent variable on the listed peer measures. The omitted category is students with $0-20 \%$ females among neighbor-5 peers. "Favored" students with non-random seat assignments are excluded from all samples. All regressions control for baseline test score, proximity of "favored" students, height, age, birth order, parental education, and baseline interest in Chinese, English, and math. Parentheses contain standard errors clustered by classroom. Permutation-based $\mathrm{p}$-values are reported in italics. 
Table A2: Effects on Communication, Seating Satisfaction, and Focus

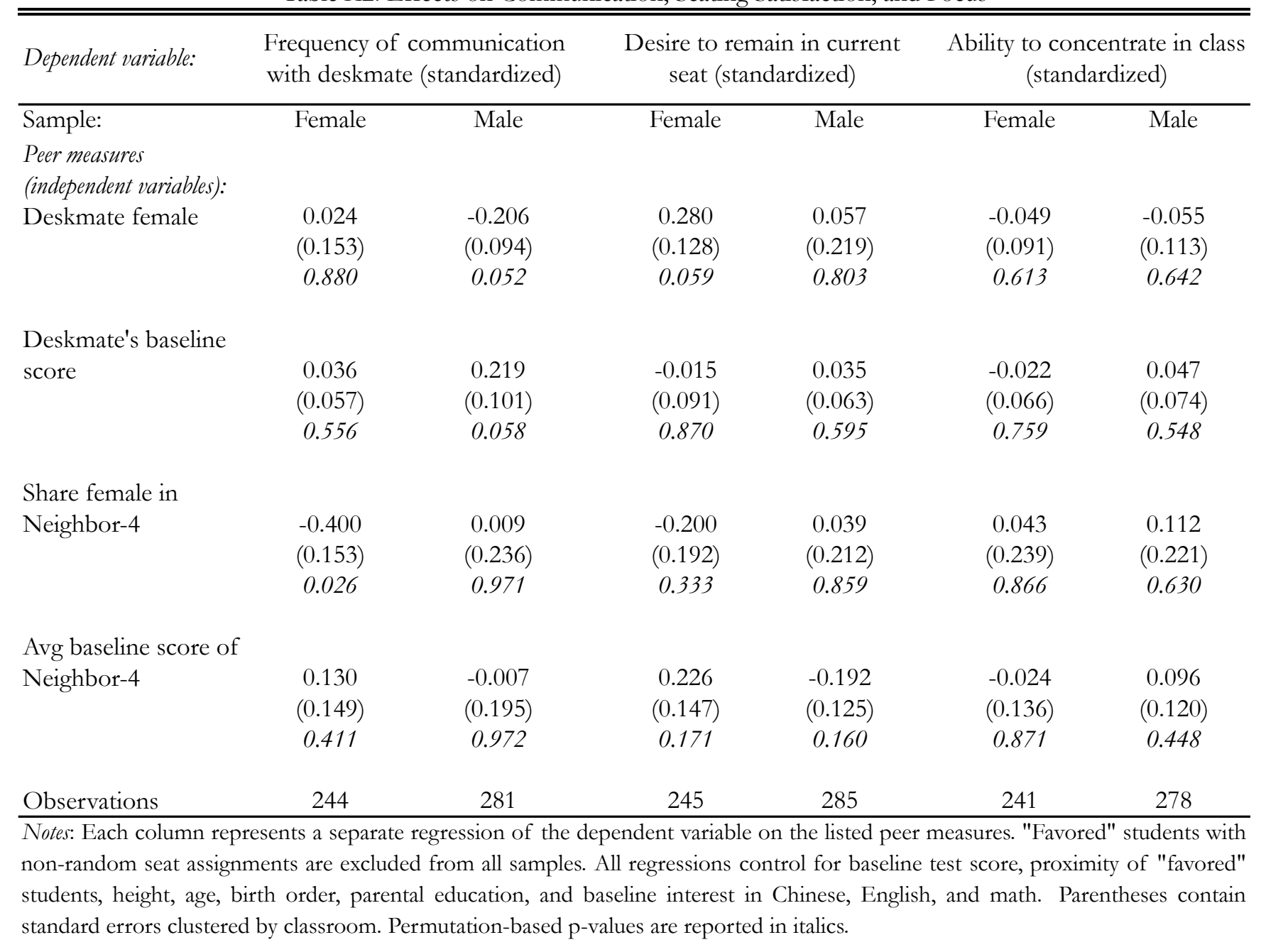

